\title{
Mujeres en venta (2015) y (des)Iguales (2015-2016): un análisis crítico de dos propuestas de documentales transmedia
}

\author{
Lucas Durr Missau*
}

Resumo: O presente artigo analisa, a partir de uma perspectiva crítica, as obras transmedia Mujeres en venta: trata de personas con fines de explotación sexual (2015) y (des)Iguales (2015-2016). Seguidamente, faz uma reflexão sobre o modelo narrativo que propõem, nomeadamente a sua estrutura e lógica, com a finalidade de entender os elementos que contribuem para sua caracterização como documentários transmedia. Palavras-chave: documentário; narrativa; transmedia.

Resumen: El presente artículo analiza las obras Mujeres en venta: trata de personas con fines de explotación sexual (2015) y (des)Iguales (2015-2016) como productos transmedia desde un punto de vista crítico. El objetivo es reflexionar sobre su modelo narrativo desde su estructura y lógica con la finalidad de entender los elementos que contribuyen a su caracterización como documentales transmedia.

Palabras clave: documental; narrativa; transmedia.

\begin{abstract}
This article analyses the productions Mujeres en venta: trata de personas con fines de explotaci $\neg o ́ n ~ s e x u a l ~(2015)$ and (des)Iguales (2015-2016) from a critic perspective. The main objective is to reflect about its narrative model, namely its structure and logic with the purpose of understanding the elements that contribute to its characterization as transmedia documentaries.

Keywords: documentary, narrative, transmedia.
\end{abstract}

Résumé: Cet article analyse les œuvres Mujeres en venta : trata de personas con fines de explotación sexual (2015) y (des)Iguales (2015-2016) à partir d'un point de vue critique. L'objectif est de réfléchir sur le modèle narratif depuis sa structure et sa logique afin de comprendre les éléments qui contribuent à sa caractérisation comme un documentaire transmédia.

Mots-clés: documentaire; narratif; transmédia.

\footnotetext{
* Doctorando. Universidad Nacional de La Plata - UNLP, Facultad de Periodismo y Comunicación Social - FPyCS, Doctorado en Comunicación. B1900ABN, La Plata, Argentina. E-mail: lucas.durr@gmail.com
}

Submissão do artigo: 18 de novembro 2015. Notificação de aceitação: 16 de fevereiro de 2016. 


\section{Introducción}

Este artículo analiza las obras Mujeres en venta: trata de personas con fines de explotación sexual $^{1}$ (2015) y (des) Iguales $^{2}$ (2015-2016) desde el modelo narrativo que proponen y que las caracteriza como documentales transmedia. La primera obra forma parte del proyecto Documedia - Periodismo Social Multimedia $^{3}$ de la Universidad Nacional de Rosario (UNR), Argentina. El proyecto fue concebido por la Dirección de Comunicación Multimedial de la misma universidad y desde 2008, año en que fue creado, se destaca por producir obras periodísticas que abordan temas sociales y por probar nuevas formas de exhibir el contenido teniendo en cuenta las potencialidades del soporte web.

Además de Mujeres en Venta, el grupo de realizadores tiene una trayectoria reconocida por realizaciones anteriores. El documental Vibrato: escuela orquesta del barrio Ludueña ${ }^{4}$ (2008) estuvo entre los finalistas en la categoría Internet del Premio Nuevo Periodismo Iberamericano CEMEX+FNPI (2009). Calles Perdidas: El Avance del Narcotráfico en Rosario ${ }^{5}$ (2013) obtuvo reconocimiento internacional en la categoría Periodismo Digital del Premio Internacional Rey de España 2013. También, las producciones Obras en Construcción $^{6}$ (2009) y Migraciones $^{7}$ (2011) integran el portfolio del equipo de la Universidad de Rosario.

El documental (des)Iguales es la primera realización transmedia de la Cátedra Latinoamericana de Narrativas Transmedia. La cátedra fue creada en 2014 por el Instituto de Cooperación Latinoamericana de la Universidad Nacional de Rosario y destacamos como sus dos objetivos principales: (1) "estimular la investigación y el desarrollo de producciones y aplicaciones transmedia (...) desde una perspectiva transdisciplinar" (Cátedra Latinoamericana de Narrativas Transmedia, 2015) y (2) "producir una publicación anual multiplataforma" (Cátedra Latinoamericana de Narrativas Transmedia, 2015).

De esta manera, en un análisis inicial de Mujeres en Venta y (des)Iguales percibimos semejanzas entre las dos obras referentes (1) al abordaje de problemas sociales y (2), en el ámbito institucional, a su relación con la Universidad

1. Mujeres en venta está disponible para visualización en: http://www.documedia.com.ar /mujeres/.

2. (des)Iguales está disponible para visualización en: http://www.des-iguales.com.

3. Más informaciones sobre el proyecto y las obras realizadas en documedia.com.ar.

4. Vibrato está disponible para visualización en: http://www.unr.edu.ar/resources/docume dia/vibrato/vibrato.htm

5. Calles Perdidas está disponible para visualización en: http://www.documedia.com.ar/ callesperdidas/.

6. Obras en Construcción está disponible para visualización en: http://www.unr.edu.ar/ resources/documedia/construccion/.

7. Migraciones está disponible para visualización en: http://www.documedia.com.ar/mi graciones/. 
Nacional de Rosario (UNR), que se presenta como un interesante escenario de producciones transmedia fuera del eje mercadológico. A pesar de las semejanzas mencionadas, las obras tienen estructuras narrativas y estrategias de acercamiento a los temas muy distintas.

Si de un lado, Mujeres en Venta tematiza la red de explotación del trabajo sexual en Argentina; por su parte, (des)Iguales enfoca las desigualdades sociales, políticas, económicas, sexuales en Latinoamérica. En este artículo, buscaremos analizar las semejanzas y las particularidades de cada una de las dos obras con la intención de comprender los aspectos que las caracterizan como documentales transmedia.

El método que utilizamos para hacer este análisis es de estudio de caso. Según Sánchez y Otero (2012: 106), es lo más adecuado para estudiar cómo se desarrolla la narrativa transmedia en las obras no-ficcionales. "Aplicándolo a nuestra área de conocimiento, el estudio de caso puede contribuir a conocer cómo se organiza y estructura (qué plataformas emplea, qué contenidos vehicula/n cada una de ellas, a qué públicos se dirigen) un ejemplo de narrativa transmedia. De esta manera, podrán comprenderse mejor sus mecanismos de funcionamiento al servicio de la historia." (Sánchez y Otero, 2012: 106-107).

La elección de Mujeres en Venta y (des)Iguales como corpus de análisis se justifica por los siguientes criterios: (1) se definen como obras de género documental transmedia; (2) no tienen la misma circulación de obras seriadas de medios hegemónicos, las cuales presentan claras estrategias mercadológicas; (3) el reconocimiento obtenido en premios internacionales de periodismo ya mencionados arriba; (4) son realizados y/o creados en la Universidad Nacional de Rosario (UNR) lo que da indicios de una escena interesante en el área.

De esta manera, el desarrollo del artículo está dividido en tres partes. Inicialmente, planteamos una discusión teórica sobre las definiciones de narrativa transmedia, su aplicación por parte del audiovisual contemporáneo, y su utilización para definir las emisiones audiovisuales. Tras este razonamiento, buscamos entender la diferenciación entre el documental multimedia interactivo y el documental transmedia con el objetivo de caracterizar este último. Posteriormente, por medio del análisis de Mujeres en Venta y (des)Iguales es posible describir y reflexionar sobre las características que definen el documental de narrativa transmedia.

\section{Narrativas transmedia: conceptos y características del relato contempo- ráneo desde una perspectiva crítica}

El contexto actual de desarrollo del proceso de convergencia mediática identificado, principalmente, por Henry Jenkins (2008) ha impulsado la apa- 
rición de nuevos modos de contar historias. En distintas áreas, desde la producción audiovisual seriada (series, novelas, películas), hasta el periodismo (grandes reportajes, documentales, entre otros), es cada vez más recurrente el uso de los términos multiplataforma, crossmedia y transmedia para definir prácticas profesionales, géneros y productos.

Antes de definir qué es la narrativa transmedia, empezamos por determinar conceptualmente los otros dos términos, los cuales nos ayudan a identificar aspectos que especifican las narrativas multimedia contemporáneas. Aunque no sea correcto establecer una escala valorativa de las obras considerada como una evolución diacrónica que ha empezado con el multiplataforma, pasando por el crossmedia, hasta llegar al transmedia; este último se ha destacado debido al carácter novedoso de los avances recientes de las tecnologías de comunicación e información.

O sea, las narrativas siempre fueron de alguna manera multiplataforma y crossmedia. Sin embargo, la aparición de las nuevas tecnologías y su relativa popularización han potenciado el desarrollo de nuevas maneras de contar las historias en los últimos años. En nuestro análisis reflexionaremos brevemente sobre los tres conceptos identificando semejanzas y diferencias con el objetivo de aclarar los límites teóricos de cada uno, lo que contribuye a pensar las obras Mujeres en Venta y (des)Iguales.

De este modo, la primera definición es que, tanto los productos transmedia, como los crossmedia y de multiple plataforms son narrativas multimediáticas. Según Sánchez y Otero (2012), desde "el plano comunicativo hablar de multimedia es hacerlo de aquellos relatos transmitidos o percibidos unitariamente a través de múltiples medios" (Sánchez y Otero, 2012: 108).

Las mismas autoras definen el relato multiplataforma como "probablemente, la forma más básica de narrativa multimedia" (Sánchez y Otero, 2012: $110)$ en que un mismo relato es narrado en diferentes medios o soportes, adaptándose el lenguaje. En este sentido, en el contexto televisivo, las narrativas multiplataforma se acercan a las ya conocidas adaptaciones. Por lo tanto, no se caracteriza como un fenómeno completamente nuevo, sino que fue impulsado por el contexto actual de desenvolvimiento tecnológico (Sánchez y Otero, 2012: 110-111).

Así como las narrativas multiplataforma, las narrativas crossmedia también se caracterizan por narrar una historia en diferentes medios y soportes. La peculiaridad de esta clase de narrativa es que:

la narración crossmedia difiere de la multiplataforma en el hecho de que no se trata de la adaptación del mismo relato a diversos soportes, sino que cada uno de ellos aportará información para la construcción de un relato unitario. El 
receptor debe experimentar el conjunto para entender el significado de cada uno de ellos. (Sánchez y Otero, 2012: 111).

Los estudios sobre el lenguaje transmedia son recientes, pero preceden los hallazgos de Henry Jenkins (2001). "Ese nuevo lenguaje denominado en 1975 por Stuart Saunders Smith como trans-media concert (Renó y Flores, 2012) fue transferido desde la música al cinema por Marsha Kinder (1991) bajo el nombre intertextualidad transmedia y, una década después, fue rebautizado y popularizada por Henry Jenkins (2001) como transmedia storytelling" (Renó, 2012: 2).

En líneas generales, de acuerdo con la definición de Jenkins (2008), son considerados transmedia aquellos relatos interrelacionados que están desarrollados en múltiples plataformas, pero que guardan independencia narrativa y sentido completo (Sánchez y Otero, 2012: 112). Para hacer la diferenciación entre los relatos transmedia y crossmedia profundizaremos la reflexión sobre las características y especificidades del primero.

Para algunos autores (Dena, 2009; Hernández y Grandío, 2011; Scolari, 2009), la narración transmediática tiene como una de sus especificidades la expansión de una historia en diferentes medios, plataformas y soportes. A diferencia del relato multiplataforma (que sigue la lógica de la adaptación) y del relato crossmedia, las expansiones transmedia se dan en múltiples medios, que aportan distintos elementos para el entendimiento de la historia simultáneamente.

Otra particularidad de las narrativas transmedia es la relación entre creadores, productos y audiencias, la cual está basada en nuevas maneras de participación, interacción y autoría. En general, los proyectos de esta clase de relatos tienen espacios determinados para la inmersión del público, de acuerdo con la plataforma elegida, que van más allá de los asignados por las obras literarias, televisivas y cinematográficas tradicionales. O sea, el usuario (que es seguidor/consumer/prosumer de un producto) actúa también en el proceso de contar la historia.

De esta manera, según Sánchez y Otero (2012: 115), podemos enumerar cuatro características comunes de la narrativa transmedia identificadas por distintos autores. La primera es que se trata de un concepto reciente lo cual supone la utilización de diversas plataformas (radio, televisión, blogs, redes sociales, páginas web, teléfonos o dispositivos móviles, etc) para desenvolver la narrativa de una misma historia. La segunda característica identificada es que cada una de las plataformas opera como un punto de entrada en la historia, pero que no es necesario conocer el contenido de cada una de ellas para entender la historia en su conjunto. 
La tercera particularidad identificada en los relatos transmedia es la "creación de contenidos específicos para cada uno de los canales de comunicación empleados, buscando una experiencia satisfactoria a través de cada uno de ellos" (Sánchez y Otero, 2012: 115). La última característica se refiere al papel activo otorgado a las audiencias, cuya curiosidad impulsa la necesidad de saber más sobre la historia narrada originando el fenómeno de los seguidores.

Por otro lado, Henry Jenkins (2009a; 2009b) enumera siete principios de las narrativas transmedia, los cuales acá presentamos de manera resumida, porque son ampliamente conocidos debido a la abundancia de obras que los han mencionado y referenciado en los últimos años:

- Expansión vs. Profundidad: es la capacidad del público de involucrarse en la circulación de los contenidos mediante las redes sociales y en el proceso de ampliar su valor económico y cultural, siendo que la profundidad es la habilidad de una persona de profundizar su experiencia de la obra hasta que llegar al núcleo duro de sus seguidores.

- Continuidad vs. Multiplicidad: es el carácter de continuidad de una obra por medio de diversas plataformas que deben ser coherentes y creíbles en relación con la narrativa como un todo. Al mismo tiempo, la multiplicidad sigue una lógica distinta en que hay cierta incoherencia del relato de la obra en relación con las historias en otras plataformas.

- Inmersión vs. Extracción: la inmersión designa la capacidad de los seguidores de ingresar en mundos ficcionales. La extracción se refiere a los elementos del relato que son transportados al mundo real, como videojuegos, juguetes, entre otros, y apropiados de manera que puedan crear otras historias.

- Construcción de mundos: se refiere a la creación de mundos que pueden soportar personajes e historias distintas a través de múltiples medios y plataformas, ofreciendo elementos también de identificación con el consumidor, además de contribuir con la inmersión y la extracción.

- Serialidad: es la propiedad de fragmentación de las historias para que sean consumidas sin un orden determinado.

- Subjetividad: se trata del proceso por el cual los seguidores comparan las experiencias de los personajes en las narrativas con aspectos de sus vivencias y perspectivas personales.

- Ejecución: la característica que designa la posibilidad de que el público pueda formar parte del relato, contribuyendo (en partes específicas de la historia) para su continuidad o expansión.

Si bien los conceptos y las características del relato que hemos descrito arriba nos ofrecen recursos analíticos para entender la utilización de elementos 
de esta clase de narrativa en el periodismo y el género documental, Mujeres en Venta y (des)Iguales son productos que circulan en ámbitos distintos a los productos analizados en gran parte de la literatura sobre transmedia storytelling. Esto es, son producciones transmedia realizadas fuera de los padrones hegemónicos y, por eso, sus particularidades deben ser consideradas en un análisis más abarcador.

Por lo tanto, la perspectiva crítica de análisis que ejercitamos en este artículo intenta entender aspectos de obras que, si por un lado no tienen un impacto significativo en la cantidad de seguidores (y consecuentemente retorno financiero), por otro actúan en la discusión de problemas sociales, obteniendo reconocimiento en otros ámbitos, como los que ya mencionamos en la introducción de este trabajo. En la próxima parte del artículo, desarrollaremos las propiedades que configuran el carácter transmediático en el ámbito periodístico y documental.

\section{Documental transmedia: conceptos, características principales y modelos}

El desarrollo tecnológico y estético de las últimas décadas ha potenciado nuevas formas de contar las historias desde el lenguaje audiovisual. En este panorama, las narrativas multimedia, sean ellas multiplataforma, crossmedia o transmedia, han dado soporte para experimentaciones en variados ámbitos en los cuales las redes sociales, la relativa popularización de los dispositivos móviles y de la web, además de otras herramientas novedosas forman parte de un ecosistema mediático con innovaciones que abarcan desde las rutinas productivas y creativas hasta el consumo.

Sin embargo, se percibe como apunta Renó (2014: 2) una escasez de estudios sobre el tema y de producciones que utilizan el modelo transmedia para la creación de relatos del género documental. También, el autor identifica que "gran parte de las obras documentales que se autodenominan transmedia son en realidad interactivas (Renó, 2011; Manovich, 2005) o construidas a partir de estrategias crossmedia o hipermedia (Landow, 2009; Gosciola, 2003). Estas estrategias son muy parecidas a la narrativa transmedia, pero no son la misma cosa. "En realidad, narrativa transmedia es más amplia y absorbe en su sistema de construcción esas dos estrategias como parte de su composición final" (Renó, 2014: 3).

El mismo autor contribuye con una definición del relato transmedia que utilizamos como uno de los fundamentos de este ejercicio de análisis que proponemos acá. Según Denis Porto Renó, "la narrativa transmedia es un lenguaje contemporáneo desarrollado por la sociedad a partir de los procesos y ambientes interactivos y que tiene como característica la difusión de mensajes 
distintos, a partir de plataformas diversas, por redes sociales y ambientes facilitadores de retroalimentación y en dispositivos móviles." (Renó, 2014: 4-5).

Como conceptos fundamentales para entender la definición de documental transmedia propuesta por Renó (2013) están el hipertexto, la hipermedia y la interactividad. Su definición de hipertexto está basada en (1) Ted Nelson (apud Landow, 2009), para el cual hipertexto es una construcción narrativa expansible, navegable, que conecta discursos textuales a través de nodos neurales; y (2) en Espen Aarshet (2005: 95), para el cual hipertexto es una herramienta para la mente, debido a su capacidad de creación de nuevas estructuras a partir de la navegación por los nodos neurales.

A su vez, Renó (2013: 97) diferencia hipermedia de hipertexto por la estructura multiplataforma del primero, que es capaz de conectar por nodos neurales y caminos navegables discursos textuales, sonoros, audiovisuales, imágenes, animaciones e infografías. Aún de acuerdo con Renó (2013: 98), la interactividad es fundamental para el documental como transmedia.

El concepto que propone toma la interactividad según la definición de Andrew Cameron (apud Shaw, 2005: 372), la cual lo define como una reconstrucción constante de nuevas estructuras de lectura desde los intereses y de las decisiones de los usuarios. Renó (2013) complementa su definición con el postulado de Manovich (2005) de que entre las variadas posibilidades interactivas existen niveles diferentes (abiertos o cerrados) determinados por la capacidad de participación y por las características de la interface.

Empezamos la caracterización del documental transmedia por su comparación con otra definición del género que se denomina documental multimedia interactivo (DMI). Esta definición del documental se acerca a la perspectiva transmedia porque ambas pretenden explorar y experimentar las potencialidades hipertextuales e hipermediáticas del soporte digital.

En el límite entre lo que caracteriza a uno y a otro está la relación que se establece entre el espectador y la obra por medio de las redes sociales. Para Renó (2011: 33), la base del cinema interactivo es que el espectador tiene cierto control sobre lo que está en la pantalla, él sabe que lo que está en la pantalla puede cambiar de acuerdo con la opción que elija.

Si bien, de una manera general, el documental multimedia interactivo tiene las mismas propiedades del transmedia, por otro lado las opciones de interactividad son limitadas. Es decir, el DMI es construido en multiplataforma con discursos complementarios e interconectados; explora el uso de textos, imágenes, videos, infografías y otras herramientas; tiene distribución en redes sociales; pero la capacidad de apropiación del contenido por parte de los usuarios en estas redes es limitada. 
Este es el punto principal que distingue el documental multimedia interactivo del documental transmedia. En la definición que usamos para este trabajo, Renó (2014: 4-5), utiliza el término retroalimentación para designar la posibilidad de que el público se relacione con las obras.

A partir de eso, el documental transmedia se particulariza por presentar multiplicidad de plataformas de lenguaje y una diversidad de mensajes independientes entre sí, aunque relacionados unos con otros. En esta perspectiva también están presentes las estructuras narrativas que proporcionan su circulación por las redes sociales (Renó, 2013: 94).

Para entender mejor cómo esos conceptos repercuten en la práctica y también en el análisis teórico sobre las producciones documentales transmedia, Renó $(2013$; 2014) expone cuatro formatos y modelos de relato en este género que ha identificado en sus investigaciones: (1) estructurado, (2) análogodigital, (3) de visualización navegable, y (4) de navegación geográfica.

El modelo estructurado, según Renó (2014: 5), se caracteriza por una navegabilidad limitada, utilizando la barra de desplazamiento vertical lo que direcciona la lectura para un modelo casi lineal. El análogo-digital es un modelo que designa las obras producidas originalmente como audiovisuales y que pasan a ser adaptadas al modelo transmedia por medio de ampliación de lenguajes (Renó, 2014: 7).

El tercer modelo es designado como de visualización navegable debido a la posibilidad de que los usuarios puedan navegar por los contenidos a través de la interfaz de la obra "como si estuvieran paseando por un museo o mismo por todo el contenido, casi físicamente" (Renó, 2014: 10-11). El último formato identificado por el autor es denominado navegación territorial, porque involucra a los usuarios en una experiencia que trasciende el ambiente virtual, haciendo que incorporen movimientos territoriales para interactuar con las obras.

Los modelos y formatos apuntados por Renó $(2013,2014)$ designan reflexiones del autor sobre producciones documentales transmedia realizadas en determinadas obras, las cuales fueron objeto de estudios de caso. Es decir, los modelos sirven para clasificar determinadas obras y como referencias para nuevos análisis y también nuevas experimentaciones del género. Lo que proponemos en este artículo es identificar los elementos que caracterizan Mujeres en Venta y (des)Iguales como documentales transmedia y, de este modo, ofrecer aportes teóricos para identificar nuevos formatos y modelos. 


\section{Mujeres en Venta y (des)Iguales: análisis de la estructura del relato y del formato propuesto}

El documental Mujeres en Venta: trata de personas con fines de explotación sexual en Argentina tiene como tema las redes de trata que captan, engañan, someten, explotan, trafican y matan mujeres en Argentina. La obra revela las singularidades de cada una de las etapas que componen el fenómeno desde las zonas de captación, hasta los lugares donde son sometidas a explotación sexual. Entre las voces que reúne en registros audiovisuales, están víctimas (que cuentan sus historias personales y experiencias de otras víctimas cercanas), investigadores sociales especialistas en el tema, miembros de instituciones públicas y representantes de organizaciones de apoyo a las víctimas.

Su narrativa está estructurada para que el usuario pueda acceder a materiales que exponen información sobre cada etapa que forma parte del proceso de explotación sexual. Empieza evidenciando las formas de captación de mujeres en barrios pobres y pequeños de regiones provinciales de Argentina, Paraguay y Uruguay, expone las principales rutas de tráfico de personas, narra la explotación sexual y muestra la actuación de instituciones en el rescate de mujeres en situación de riesgo.

Más allá del rico material de investigación periodística y de producción gráfica y audiovisual, Mujeres en Venta es un modelo novedoso de documental transmedia. En líneas generales, si pensamos a partir de las características delineadas previamente en este artículo, la obra está compuesta por contenidos que se expanden, están disponibles en múltiples plataformas y posibilitan en este contexto la retroalimentación por medio de redes sociales y otras herramientas.

De acuerdo con la clasificación de formatos y modelos de Renó (2013, 2014), podemos caracterizar Mujeres en Venta como un documental transmedia de visualización navegable. Sin embargo, la forma en que está concebida su visualización aporta contribuciones a la definición propuesta por Renó ya que el usuario recorre el contenido de manera diferente a la ejemplificada en la definición del autor. Si bien se puede usar la barra de desplazamiento vertical de la página web donde está la obra para acceder a los contenidos audiovisuales, Mujeres en Venta tiene disponible lo que denominan "Recorrido Transmedia".

Por medio de este recorrido (también utiliza la barra de desplazamiento vertical para navegar por los contenidos), se exponen al usuario los variados tipos de contenido en distintas plataformas como: un mapa colaborativo de la red de trata de mujeres, un comic, audios, fotos, videos cortos, un documental de larga duración, además de materiales de campañas sobre el tema con la utilización de qr-codes y de realidad aumentada. De este modo, por medio de 
la barra de desplazamiento el usuario navega por las etapas que componen el sistema de explotación sexual. Dichas etapas son narradas en videos cortos con declaraciones de víctimas y otras personas involucradas en el tema, que a su vez se complementan con datos expuestos gráficamente en la página.

A través del "Recorrido Transmedia" se accede al material multiplataforma, interactivo y que posibilita la retroalimentación del contenido haciendo posible que el público forme parte del relato. En este sentido, destacamos el mapa colaborativo. Más allá de poder visualizar las principales regiones argentinas donde hay mujeres desaparecidas, mujeres rescatadas y lugares de explotación, el usuario puede contribuir en su elaboración y actualización enviando su reporte.

El comic Mujeres en Venta: Periodismo en viñetas cuenta la historia de una adolescente, natural de Paraguay, víctima de explotación sexual que escapa de la red de trata de personas. La narrativa fue construida a partir de la sentencia judicial de un caso juzgado en la ciudad de Rosario, Argentina, en 2012. La serie está compuesta por cinco historias publicadas con el semanario El Eslabón disponible para los suscriptores del periódico.

La parte del recorrido destinada a las imágenes que retratan aspectos de la producción de Mujeres en Venta tiene una característica interesante. "La galería de fotos se actualiza conforme avanzan las líneas narrativas del relato de Documedia en sus diferentes soportes y plataformas." (Mujeres en Venta, 2014).

Entre los audiovisuales producidos, están los denominados en la obra como "Micros". Son cuatro obras de cinco minutos emitidas por el Canal 3 en la ciudad de Rosario. El material está disponible en la parte destinada a los "Micros" en el "Recorrido Transmedia". Emitido por el mismo canal de televisión en Rosario y disponible en la página de Mujeres en Venta, está el documental de 26 minutos intitulado "Historias silenciadas". Otra serie de audiovisuales que ofrece la obra son los "Movisodios", se trata de cinco videos cortos de tres minutos de duración creados para el consumo desde dispositivos móviles.

Por último, forman parte del "Recorrido Transmedia" las campañas de difusión de la obra y del tema que trata la obra. Los afiches creados tienen recursos de qr-codes y de realidad aumentada posibilitando que los espectadores puedan interactuar con contenidos específicos e ingresar en la narrativa de Mujeres en Venta. En la página que reúne los materiales del documental también se puede acceder a las piezas de la campaña de sensibilización a la trata de personas creadas para proyectarse en pantallas de LED en distintos lugares de la ciudad. 
Con respecto a las herramientas de redes sociales, Mujeres en Venta trae como opciones durante las dos alternativas de recorridos la posibilidad de acceder a nuevos contenidos en Facebook, Twitter y Youtube. Cada una con contenidos específicos que extrapolan los límites del universo narrativo de la obra.

Por su parte, (des)Iguales es una obra transmedia todavía en proceso de elaboración y con previsión de ejecución para los años de 2015-2016. Fue pensada dentro del marco conceptual y teórico de la Cátedra Latinoamericana de Narrativas Transmedia, en 2015. Su temática enfoca las desigualdades sociales, políticas, económicas, sexuales, entre otras practicadas en Latinoamérica, a las cuales pretende visualizar y dar visibilidad utilizando las posibilidades del relato transmedia.

En este sentido, (des)Iguales difiere de Mujeres en Venta porque el primero tiende a priorizar las potencialidades colaborativas y territoriales de las plataformas disponibles. Por ese motivo, si bien lo clasificamos según los formatos y modelos de Renó $(2013,2014)$ como documental transmedia de navegación territorial, tenemos que considerar la expansión propuesta por el documental en términos de la cobertura territorial que se propone abarcar y también de la relevancia de la participación del espectador en la construcción del relato, la cual va más allá del uso de redes sociales como Facebook, ${ }^{8}$ Twitter, ${ }^{9}$ Youtube, ${ }^{10}$ Instagram ${ }^{11}$ y Vine. ${ }^{12}$

La amplitud del territorio que busca abarcar (des)Iguales se extiende por los países de Latinoamérica. Para eso, cuenta con la participación de usuarios de lugares diferentes por medio de envíos de relatos, declaraciones audiovisuales en que los participantes narran los problemas de sus localidades. Además, los usuarios pueden ubicar sus envíos ayudando a componer un mapa de visualización de las desigualdades publicado en la página de la obra. Los usuarios también pueden agregar fotos y otros datos en el mapa.

De esta forma, para cada etapa de desarrollo del documental es expuesto un tema distinto referente a las diferencias sociales. Por ejemplo, riqueza, justicia, participación política, género, sexualidad, movilidad, están entre los elegidos como ejes temáticos del relato. En cada eje, los usuarios producen documentales cortos sobre la realidad local de la que forman parte, los alojan

8. Utiliza la fanpage del Proyecto Desiguales, disponible en http://facebook.com/proyec todesiguales.

9. Utiliza la hashtag \#DesIguales y el perfil des_iguales, disponible en http://twitter.com/ des_iguales.

10. Utiliza el canal Proyecto Desiguales, en https://www.youtube.com/channel/UCnvEKZW YIXs-TGCXAIz4Y9A.

11. Utiliza la hashtag \#Desiguales.

12. También utiliza la hashtag \#Desiguales. 
en Youtube, desde donde automáticamente son publicados en la página de la obra y pueden ser visualizados.

Posteriormente, los materiales de estos documentales son editados y convertidos en videos de uno a dos minutos, a los cuales son asociados recursos de realidad aumentada y de localización. La idea es pegar los dispositivos de realidad aumentada en paredes y muros en diferentes lugares/ciudades de Latinoamérica. A través de las redes sociales, los participantes pueden enviar registros del proceso de producción y de visualización de dichos dispositivos.

También, se invitará a los usuarios a registrar la experiencia de producción, pegatina y visualización de realidad aumentada por las calles de las ciudades de Latinoamérica. El registro podrá hacerse en varios formatos. Podrán utilizarse plataformas sociales de distribución de contenidos como Facebook, Twitter, Instagram y Vine. Al final del proyecto, será elaborado un libro en multiplataforma, que será en español y portugués.

\section{Conclusiones}

Los estudios del fenómeno transmedia en el campo comunicacional han alcanzado cierto protagonismo en los últimos años. Sin embargo, la investigación de obras transmediáticas aún es novedosa y carece de análisis que abarquen más allá de la producción de obras audiovisuales con amplio alcance mercadológico. Es en este sentido que hemos ejercitado el análisis de obras que proponen generar cambios sociales y pautan sus realizaciones en problemas de orden económico, político, social y cultural.

Mujeres en Venta y (des)Iguales están compuestos por materiales que nos hacen extrapolar el examen de carácter técnico del relato transmedia. Para este artículo, nos enfocamos en identificar los elementos que caracterizan las dos obras como documentales transmedia e, infelizmente, no abarcamos en la discusión aspectos de la rutina de producción y del contenido tematizado. Estos dos puntos contribuirían a la discusión sobre las transformaciones que vienen impactando el periodismo en los últimos años. Desde esta perspectiva, sería posible entender el valor cultural y social de las producciones transmedia, más allá de medir su innovación tecnológica y consecuente potencial mercadológico.

En general, además de tratar de temáticas de carácter social, Mujeres en Venta y (des)Iguales tienen en común la utilización de recursos novedosos para contar las historias. Si bien se pueden caracterizar como documentales transmedia con formatos clasificados y previstos conceptualmente por Renó (2013, 2014), las dos obras proponen en la estructura de sus relatos intensificar la experiencia del usuario por medio de la retroalimentación, lo que hace que 
estos documentales actúen como importantes vectores en la actualización de los modelos narrativos descritos por el mismo autor.

En este sentido, el aporte de Mujeres en Venta es el "Recorrido Transmedia", por medio del cual el público accede al material multiplataforma e interactúa con la obra también produciendo contenido desde las posibilidades previstas. A su vez (des)Iguales potencia la colaboración del usuario a través de la ampliación del alcance territorial sumada a distintas alternativas de expansión de la narrativa con la participación de la audiencia.

Si bien hemos podido avanzar en la discusión sobre nuevas propuestas de documentales transmedia, identificamos que todavía hay aristas a ser sanadas, específicamente, sobre el género documental y su relación con el periodismo, en el contexto transmediático. Las dos obras que hemos analizado nos dan indicios materiales para reflexiones posteriores con este enfoque.

\section{Referencias bibliográficas}

Aarseth, E. (2006). Sin sensación de final: estética hipertextual. In Ma. T. P. Villariño \& A. A. González, Teoría del hipertexto: la literatura en la era electrónica. Madri: Arco Libros.

CLNT (2015). Cátedra Latinoamericana de Narrativas Transmedia, disponible en http://catedratransmedia.com.ar. consultado el 11/09/2015.

Dena, C. (2009). Transmedia pactice: theorising the practice of expressing a fictional world across distinct media and environments. Tesis doctoral presentada en el Departament of Media and Communications, University of Sydney. Disponible en http://www.scribd.com/doc/52231937/DENAT ransmediaPractice

Gosciola, V. (2003). Roteiro para as novas mídias: do game à TV interativa. São Paulo: Editora Senac São Paulo.

Hernández Pérez, M. \& Grandío, M.M. (2011). Narrativa crossmedia en el discurso televisivo de Ciencia Ficción. Estudio de Battlestar Galactica (2003-2010). Revista Área Abierta, 28. Disponible en http://revistas.ucm. es/index.php/ARAB/article/download/.../4031

Jenkins, H. (2009a). The Revenge of the Origami Unicorn: Seven Principles of Transmedia Storytelling (Well, Two Actually. Five More on Friday). Disponible en http://henryjenkins.org/2009/12/the_revenge_of_the_origami _uni.html

Jenkins, H. (2009b). The Revenge of the Origami Unicorn: The Remaining Four Principles of Transmedia Storytelling. Disponible en: http://hen ryjenkins.org/2009/12/revenge_of_the_origami_unicorn.html 
Jenkins, H. (2008). Cultura de la convergencia. Barcelona: Paidós.

Jenkins, H. (2001). Convergence? I Diverge. Technology Review.

Kinder, M. (1991). Playing with Power in Movies, Television, and Video Games: From Muppet Babies to Teenage Mutant Ninja Turtles. Berkeley and Los Angeles, California: University of California Press.

Landow, G. (2009). Hipertexto 3.0. Barcelona: Paidós Ibérica.

Manovich, L. (2005). El lenguaje de los nuevos medios de comunicación: la imagen en la era digital. Buenos Aires: Paidós Comunicación.

Renó, D. (2014). Diversidad de formatos para documentales transmedia, VI Congreso Internacional Latina de Comunicación Social, VI CILCS, Universidad de La Laguna.

Renó, D. (2013). Diversidades de modelos narrativos para documentários transmídia. Revista Doc Online, 14, Agosto. Disponible en: http://www. doc.ubi.pt/14/dossier_denis_reno.pdf. Consultado el 02/09/2015.

Renó, D. (2011). Cinema interativo e linguagens audiovisuais interativas: como producir. Tenerife: Editora ULL.

Renó, D. \& Flores, J. (2012). Periodismo transmedia. Madrid: Fragua editorial.

Sanchez, C.C. \& Otero, T.P. (2012). Nuevas narrativas audiovisuales. ICONO 14, 10(2): 102-125. ISSN 1697-8293. Madrid, España.

Scolari, C. (2009). Transmedia storytelling: Implicit consumers, narrative worlds, adn branding y contemporaru media production. International Journal of Communication, 3: 586-606.

Shaw, J. (2005). O cinema digitalmente expandido: o cinema depois do filme. In L. Leão (org.). O chip e o caleidoscópio: reflexões sobre as novas mídias. São Paulo: SENAC.

\section{Filmografía}

(des)Iguales (2015-2016), de la Cátedra Latinoamericana de Narrativas Transmedia. Disponible para visualización en http://www.des-iguales.com.

Mujeres en venta: trata de personas con fines de explotación sexual (2015), de DocuMedia Periodismo Social Multimedia. Disponible para visualización en http://www.documedia.com.ar/mujeres/.

Calles Perdidas: El Avance del Narcotráfico en Rosario (2013), de DocuMedia Periodismo Social Multimedia. Disponible para ser visualizado en http://www.documedia.com.ar/callesperdidas/. 
Migraciones (2011), de Fernando Irigaray. Disponible para visualización en http://www.documedia.com.ar/migraciones/.

Obras en Construcción (2009), de Fernando Irigaray. Disponible para visualización en http://www.unr.edu.ar/resources/documedia/construccion/.

Vibrato: escuela orquesta del barrio Ludueña (2008), de Fernando Irigaray. Disponible en http://www.unr.edu.ar/resources/documedia/vibrato/vibrat o.htm. 